\title{
Hypothalamic-pituitary-adrenal axis in patients with ankylosing spondylitis
}

\author{
Mehmet Kirnap ${ }^{1}$, Hulusi Atmaca ${ }^{2}$, Fatih Tanriverdi ${ }^{2}$, Osman Ozsoy ${ }^{1}$, \\ Kursad Unluhizarci ${ }^{2}$, Fahrettin Kelestimur ${ }^{2}$
}

${ }^{1}$ Department of Physical Medicine and Rehabilitation, ${ }^{2}$ Department of Endocrinology and Metabolism, Erciyes University Medical School, Kayseri, Turkey

\begin{abstract}
OBJECTIVE: To investigate the hypothalamic-pituitary-adrenal (HPA) axis via the insulintolerance test (ITT), standard-dose $(250 \mu \mathrm{g})$ ACTH test (SDT) and low-dose (1 $\mu \mathrm{g})$ ACTH test (LDT) in patients with ankylosing spondylitis (AS). DESIGN: The study group included 13 male patients with AS who were diagnosed according to the Modified New York criteria, and 8 healthy male subjects and was carried out at the Department of Physical Medicine and Rehabilitation, Erciyes University Medical School. ACTH stimulation tests were carried out by using $1 \mu \mathrm{g}$ and $250 \mu \mathrm{g}$ i.v. ACTH as a bolus injection, and blood samples were drawn at 0,30 and $60 \mathrm{~min}$. ITT was performed by using intravenous (i.v.) soluble insulin, and serum glucose and cortisol levels were measured before and after 30, 60,90 and $120 \mathrm{~min}$. All of the tests were performed consecutively with 3-day intervals, after an overnight fast. RESULTS: There were no significant differences between the patients with AS (mean age $36.9 \pm 6.7$ years) and the healthy subjects (mean age $37.4 \pm 5.7$ years) in terms of age. The basal cortisol levels in the AS group measured during LDT, SDT and ITT $(556 \pm 204 \mathrm{nmol} / \mathrm{l} ; 524 \pm 169 \mathrm{nmol} / \mathrm{l} ; 418 \pm 232 \mathrm{nmol} / \mathrm{l}$, respectively) were comparable to the values of the control group $(572 \pm 199 \mathrm{nmol} / \mathrm{l} ; 520 \pm 182$ $\mathrm{nmol} / \mathrm{l} ; 424 \pm 194 \mathrm{nmol} / \mathrm{l}$, respectively). There were also no significant differences in peak cortisol responses between the two groups using LDT (patients $1025 \pm 339 \mathrm{nmol} / \mathrm{l}$; controls $844 \pm 236$ $\mathrm{nmol} / \mathrm{l}$ ), SDT (patients $1082 \pm 243 \mathrm{nmol} / \mathrm{l}$; controls $1120 \pm 131 \mathrm{nmol} / \mathrm{l}$ ) and ITT (patients $834 \pm 256$ $\mathrm{nmol} /$; controls $820 \pm 239 \mathrm{nmol} /$ ). CONCLUSION: In contrast with findings in other inflammatory diseases such as rheumatoid arthritis and polymyalgia rheumatica, the present data indicate that there is no apparent abnormality of the HPA axis activity in patients with AS.
\end{abstract}

Key words: ACTH stimulation test, Anklylosing Spondylitis, Hypothalamic Pituitary Adrenal Axis, Inflammatory disease, Insulin tolerance test

Address for correspondence:

Fahrettin Kelestimur, MD, Erciyes University Medical School, Department of Endocrinology, 38039, Kayseri, Turkey, Tel: +90 352 4374901/21900, Fax: +90 352 4375807, e-mail: fktimur@erciyes.edu.tr

Received 14-12-07, Revised 20-04-08, Accepted 16-05-08

\section{INTRODUCTION}

Ankylosing spondylitis (AS) is a rheumatic disorder of unknown etiology, involving especially the sacroiliac joints and the vertebrae with variable degrees of systemic involvement. The pathogenesis of AS is poorly 
understood. However, immune mediated mechanisms involving human leucocyte antigen (HLA)-B27, inflammatory cellular infiltrates, cytokines (e.g tumor necrosis factor alpha, interleukin 10) genetic and environmental factors are thought to play key roles. ${ }^{1,2}$ Increasing evidence demonstrates bi-directional interactions between the neuroendocrine and immune systems. The hypothalamic-pituitary-adrenal (HPA) axis plays a pivotal role in the coordinated physiological response to stress, including the inflammatory and pain states of many rheumatic diseases. It has been suggested that a disruption in the neuroendocrine-immune system may be important in the pathogenesis of rheumatic diseases. ${ }^{3}$ In contrast to other rheumatic diseases such as rheumatoid arthritis, few studies ${ }^{1}$ have investigated HPA axis activity in AS. In the present study, we evaluated the HPA axis in patients with AS by using dynamic tests. We assessed the HPA axis by insulin tolerance test (ITT), which is accepted as the gold standard in the investigation of HPA axis integrity, by standard-dose ACTH $(250 \mu \mathrm{g})$ stimulation test (SDT) in which the dose of ACTH is supraphysiological and by low-dose ACTH $(1 \mu \mathrm{g})$ test (LDT), which has been suggested as a physiological test in the investigation of the HPA axis. ${ }^{4}$

\section{PATIENTS AND METHODS}

The study group included 13 male patients with AS diagnosed according to the Modified New York criteria, ${ }^{5}$ who were seen in the Outpatient Clinic of the Department of Physical Medicine and Rehabilitation in the Erciyes University Medical School between May 1999 and May 2000. The duration of the disease was more than 3 years (range 3-8 years) in all patients. None of the patients had been treated previously with glucocorticoids. Patients with another disease or under medications known to affect the HPA axis were not included in the study. The patients had been receiving only non-steroidal anti-inflammatory drugs such as indomethacin which were withdrawn $1 \mathrm{wk}$ before the investigation. Eight healthy male volunteers served as control subjects. The study was approved by the hospital's Medical Ethics Committee and informed consent was obtained from the subjects. Patients and controls underwent $1 \mu \mathrm{g}$ and $250 \mu \mathrm{g}$ intravenous (i.v.) ACTH stimulation tests and ITT which were initiated at between 08.00 and $09.00 \mathrm{~h}$ after an overnight fast.
All of the tests were performed consecutively with a 3day free interval. ACTH was given as a bolus injection and blood samples were drawn at 0,30 and $60 \mathrm{~min}$. Two hundred and fifty micrograms of tetracosactrin (Synacthen, Nürnberg, Germany) were diluted in sterile saline solution to a concentration of $5 \mu \mathrm{g} / \mathrm{ml}$ in plastic tubes and kept at $+4^{\circ} \mathrm{C}$ maximally for 4 months. Further dilution was performed by taking $0.2 \mathrm{ml}$ of this solution and adding $0.8 \mathrm{ml}$ of saline solution immediately prior to IV administration. ${ }^{4}$ ITT was performed by using i.v. soluble insulin $(0.1 \mathrm{IU} / \mathrm{kg}$ regular insulin) and serum glucose and cortisol levels were measured before and after 30, 60, 90 and 120 $\mathrm{min}$. Serum glucose levels less than $2.2 \mathrm{nmol} / \mathrm{l}$ were achieved in all patients during the ITT. The cortisol responses were expressed as absolute values and as the area under the curve (AUC) calculated by the trapezoidal integration ( $\mathrm{AUCs}_{0-60}$ for $\mathrm{ACTH}$ tests and $\mathrm{AUCs}_{0-120}$ for ITT).

The serum samples were stored at $-20^{\circ} \mathrm{C}$ until assayed. Serum cortisol levels were determined by radioimmunoassay (RIA) using a commercially available kit (ICN, Biomedicals, Costa Mesa, CA, USA). The intra- and interassay coefficients of variation were $5.8 \%$ and $6.5 \%$, respectively. Blood glucose levels were determined by the glucose oxidase method (RAXT auto-analyzer, USA).

Results are expressed as mean \pm S.D. in the text and tables. Statistical comparisons were made using the Mann-Whitney U-test. $\mathrm{P}<0.05$ was considered statistically significant.

\section{RESULTS}

Six patients had bilateral sacroiliitis grade 4 , one patient had bilateral sacroiliitis grade 3 and six had bilateral sacroiliitis grade 2 . There were no significant correlations of cortisol levels with disease duration or of cortisol levels with sacroiliitis grade. There were no significant differences between the patients with AS (mean age 36.9 \pm 6.7 years; range 24-45) and the healthy subjects (mean age $37.4 \pm 5.7$ years; range 25-46) in terms of age.

Basal cortisol levels in the AS group measured at time zero of LDT, SDT and ITT were comparable to those in the control group (Table 1). The average levels of basal cortisol obtained at zero time of the various 
tests (LDT, SDT and ITT) were also comparable in the two groups (Table 1). There were no significant differences in the peak (Table 2) and AUC (Table 3) cortisol responses during LDT, SDT and ITT between the controls and the patients with AS.

Table 1. Basal cortisol (nmol/l) levels in patients and controls.

\begin{tabular}{lccc}
\hline $\begin{array}{l}\text { Basal cortisol levels } \\
\text { at zero time of }\end{array}$ & $\begin{array}{c}\text { AS } \\
(\mathbf{n = 1 3})\end{array}$ & $\begin{array}{c}\text { Controls } \\
(\mathbf{n = 8})\end{array}$ & P value \\
\hline LDT & $556 \pm 204$ & $572 \pm 199$ & 0.770 \\
SDT & $524 \pm 169$ & $520 \pm 182$ & 0.885 \\
ITT & $418 \pm 232$ & $424 \pm 194$ & 0.717 \\
$\begin{array}{l}\text { Average value of basal } \\
\text { cortisol levels }\end{array}$ & $499 \pm 134$ & $505 \pm 165$ & 0.940 \\
\hline
\end{tabular}

AS; Ankylosing spondylitis, LDT; Low-dose ACTH test, SDT; Standard-dose ACTH test, ITT; Insulin tolerance test Results are expressed as mean \pm S.D.

Table 2. Peak cortisol (nmol/l) responses to insulin tolerance test, low and standard-dose ACTH tests in patients with ankylosing spondylitis and controls.

\begin{tabular}{lccc}
\hline Test & $\begin{array}{c}\text { AS }(\mathbf{n}=\mathbf{1 3}) \\
\text { Peak cortisol level }\end{array}$ & $\begin{array}{c}\text { Controls }(\mathbf{n}=8) \\
\text { Peak cortisol level }\end{array}$ & $\begin{array}{c}\text { P } \\
\text { value }\end{array}$ \\
\hline $\begin{array}{l}\text { Low-dose } \\
\text { ACTH test }\end{array}$ & $1025 \pm 339$ & $844 \pm 236$ & 0.199 \\
$\begin{array}{l}\text { Standard-dose } \\
\text { ACTH test }\end{array}$ & $1082 \pm 243$ & $1120 \pm 131$ & 0.850 \\
$\begin{array}{l}\text { Insulin } \\
\text { tolerance test }\end{array}$ & $834 \pm 256$ & $820 \pm 239$ & 0.843 \\
\hline
\end{tabular}

AS; Ankylosing spondylitis. Results are expressed as mean \pm S.D.

Table 3. The AUC (area under the curve) values of cortisol during an insulin tolerance test (nmol/lx120 min), low and standard-dose ACTH tests (nmol/lx60 min) in the two groups.

\begin{tabular}{lccc}
\hline Test & AS $(\mathbf{n}=13)$ & Controls $(\mathbf{n}=8)$ & P value \\
\hline $\begin{array}{l}\text { Low-dose } \\
\text { ACTH test }\end{array}$ & $49789 \pm 15427$ & $43816 \pm 12064$ & 0.444 \\
$\begin{array}{l}\text { Standard-dose } \\
\begin{array}{l}\text { ACTH test } \\
\text { Insulin } \\
\text { tolerance test }\end{array}\end{array}$ & $71414 \pm 2046 \pm 10574$ & $54110 \pm 8797$ & 0.315 \\
\hline
\end{tabular}

AS; Ankylosing spondylitis. Results are expressed as mean \pm S.D.

\section{DISCUSSION}

The proinflammatory cytokines, notably interleukin-1 (IL-1), interleukin-6 (IL-6) and tumor necrosis factor-alpha (TNF- $\alpha$ ), may increase ACTH secretion either directly or by augmenting the effect of corticotrophin-releasing factor., Ankylosing spondylitis is a chronic, progressive rheumatic disorder of unknown etiology characterized by an inflammation leading to bone fusion of the vertebral joints. Cytokines, especially IL-1, IL-6, interleukin 8 (IL-8) and TNF- $\alpha$, are mediators of the inflammatory process of rheumatoid arthritis and are associated with disease activity. ${ }^{3,6} \mathrm{~A}$ relationship has also been shown between disease activity in AS and IL-6, soluble interleukin 2 (IL-2) receptors and TNF- $\alpha .{ }^{7,8}$ Endogenous glucocorticoids produced by the adrenal glands, under the control of the hypothalamus and pituitary, have an important role in the control of inflammation. It is now clear that the presence of inflammation, through the release of cytokines, constitutes a direct stimulus to the activity of the hypothalamus and pituitary, resulting in the production of adrenal glucocorticoids under the influence of ACTH. As glucocorticoids inhibit several components of the immune-inflammatory response, including the production of cytokines, a classical negative feedback control loop ensues. ${ }^{9}, 10$ Several studies have shown an altered HPA axis activity in inflammatory rheumatic diseases such as rheumatoid arthritis ${ }^{11,12}$ and polymyalgia rheumatica. ${ }^{12-14}$ It is well known that the frequency and severity of AS show a male preponderance. ${ }^{1,2}$ Due to this gender imbalance, most studies have focused on sex hormones,${ }^{15}$ while pituitary hormones have not generally been measured. Straub et a ${ }^{16}$ reviewed the literature, including studies performed between 1992 and 2000 regarding AS, and concluded that deficiency in the secretion or production of adrenal, gonadal and pituitary hormones could not be demonstrated. Basal cortisol and the major adrenal androgen dehydroepiandrosterone sulphate (DHEAS) were found to be normal in AS. ${ }^{17,18}$ To our knowledge, there is only one study in which HPA axis activity was assessed by dynamic test. ${ }^{19}$ Imrich et al found no differences in basal cortisol, ACTH, DHEAS and $17 \alpha$-hydroxyprogesterone levels, and ACTH and cortisol responses to ITT between 17 patients with AS and 11 healthy controls. In the AS group, they found higher IL- 6 and TNF $\alpha$ compared to the controls. Normal HPA axis activity in AS has been 
explained by subtle inflammation-induced changes that cannot be revealed by testing so far applied. ${ }^{16} \mathrm{We}$ therefore aimed to investigate the HPA axis by ITT, LDT and SDT, which are the most widely used tests for the assessment of the HPA axis. ITT has been accepted as the gold standard for the assessment of adrenal insufficiency. ${ }^{20} \mathrm{We}$ recently ${ }^{21}$ evaluated the HPA axis of 16 patients with primary fibromyalgia syndrome and found that 6 out of the 16 patients had subnormal adrenal cortisol responses, which were revealed by LDT but not by SDT or ITT. It has been suggested that the $1 \mu \mathrm{g}$ ACTH test is more sensitive than a $250 \mu \mathrm{g}$ ACTH test in the assessment of HPA axis activity. ${ }^{21,22}$

In the present study, we found that both basal cortisol values and peak cortisol responses during LDT, SDT and ITT in AS patients were comparable to those in healthy controls. In contrast to findings in other inflammatory diseases such as rheumatoid arthritis and polymyalgia rheumatica, there is no apparent abnormality of HPA axis activity in patients with AS. In conclusion, although AS is an inflammatory disease, HPA axis function in such patients is not affected.

\section{REFERENCES}

1. Sieper J, Braun J, Rudwaleit M, Bonen A, Zink A, 2002 Ankylosing spondylitis: an overview. Ann Rheum Dis 61: Suppl 3: iii8-18.

2. Khan MA, 2002 Update on spondyloarthropathies. Ann Intern Med 136: 896-907.

3. Crofford LJ, 2002 The hypothalamic-pituitary-adrenal axis in the pathogenesis of rheumatic diseases. Endocrinol Metab Clin North Am 31: 1-13.

4. Dickstein G, Spigel D, Arad E, Shechner C, 1997 One microgram is the lowest ACTH dose to cause a maximal cortisol response. There is no diurnal variation of cortisol response to submaximal ACTH stimulation. Eur J Endocrinol 137: 172-175.

5. van der Linden S, Valkenburg HA, Cats A, 1984 Evaluation of diagnostic criteria for ankylosing spondylitis. A proposal for modification of the New York criteria. Arthritis Rheum 27: 361-368.

6. Gaillard RC, 1994 Neuroendocrine-immune system interactions. The immune-hypothalamo-pituitary-adrenal axis. Trends Endocrinol Metab 5: 303-309.

7. Gratacos J, Collado A, Filella X, et al, 1994 Serum cytokines (IL-6, TNF- $\alpha$, IL-1 $\beta$ and INF- $\gamma$ ) in ankylosing spondylitis: a close correlation between serum IL-6 and disease activity and severity. Br J Rheumatol 10: 927931.
8. Toussirot E, Lafforgue P, Boucraut J, Despieds P, Schiano A, Bernard D, 1994 Acquaviva PC, Serum levels of interleukin 1-beta, tumor necrosis factor-alpha, soluble interleukin 2 receptor and soluble CD8 in seronegative spondyloarthropathies. Rheumatol Int 13: 175-180.

9. Morand EF, Leech M, 2001 Hypothalamic-pituitaryadrenal axis regulation of inflammation in rheumatoid arthritis. Immunol Cell Biol 79: 395-399.

10. Chrousos GP, 1995 The hypothalamic-pituitary-adrenal axis and immune-mediated inflammation. $\mathrm{N}$ Engl $\mathrm{J}$ Med 332: 1351-1362.

11. Demir H, Keleştimur F, Tunç M, Kırnap M, Özugul Y, 1999 Hypothalamo-pituitary-adrenal axis and growth hormone axis in patients with rheumatoid arthritis. Scand J Rheumatol 28: 41-46.

12. Cutolo M, Foppiani L, Minuto F, 2002 Hypothalamicpituitary-adrenal axis impairment in the pathogenesis of rheumatoid arthritis and polymyalgia rheumatica. $\mathbf{J}$ Endocrinol Invest 25: Supp 10: 19-23.

13. Cutolo M, Straub RH, Foppiani L, et al, 2002 Adrenal gland hypofunction in active polymyalgia rheumatica. Effect of glucocorticoid treatment on adrenal hormones and interleukin 6. J Rheumatol 29: 748-756.

14. Demir H, Tanriverdi F, Ozogul N, et al, 2006 Evaluation of the hypothalamic-pituitary-adrenal axis in untreated patients with polymyalgia rheumatica and healthy controls. Scand J Rheumatol 35: 217-223.

15. Masi AT, 1992 Do sex hormones play a role in ankylosing spondylitis? Rheum Dis Clin North Am 18: 153-176.

16. Straub RH, Struharova S, Scholmerich J, Harle P, 2002 No alterations of serum levels of adrenal and gonadal hormones in patients with ankylosing spondylitis. Clin Exp Rheumatol 20: Suppl 28: S52-S59.

17. Arniaud D, Mattei JP, Boyer J, Roux H, 1998 Sex hormones in spondylarthropathies. A study in 57 patients. Rev Rhum Engl Ed 65: 21-26.

18. Hedman M, Nilsson E, de la Torre B, 1992 Low blood and synovial fluid levels of sulpho-conjugated steroids in rheumatoid arthritis. Clin Exp Rheumatol 10: 25-30.

19. Imrich R, Rovensky J, Zlnay M, et al, 2004 Hypothalamicpituitary-adrenal axis function in ankylosing spondylitis. Ann Rheum Dis 63: 671-674.

20. Grinspoon SK, Biller BM, 1994 Clinical review 62: Laboratory assessment of adrenal insufficiency. J Clin Endocrinol Metab 79: 923-931.

21. Kirnap M, Colak R, Eser C, Ozsoy O, Tutus A, Kelestimur F, 2001 A comparison between low-dose (1 microg), standard-dose (250 microg) ACTH stimulation tests and insulin tolerance test in the evaluation of hypothalamopituitary-adrenal axis in primary fibromyalgia syndrome. Clin Endocrinol 55: 455-459.

22. Dokmetas HS, Colak R, Kelestimur F, Selcuklu A, Unluhizarci K, Bayram F, 2000 A comparison between the 1-microg adrenocorticotropin (ACTH) test, the short ACTH (250 microg) test, and the insulin tolerance test in the assessment of hypothalamo-pituitary-adrenal axis immediately after pituitary surgery. J Clin Endocrinol Metab 85: 3713-3719. 